\title{
The potential of drug repositioning as a short-term strategy for the control and treatment of COVID-19 (SARS-CoV-2): a systematic review
}

\author{
William Gustavo Lima ${ }^{1,2}\left(\right.$ D . Júlio César Moreira Brito ${ }^{1,3} \cdot$ Joerg Overhage ${ }^{4} \cdot$ Waleska Stephanie da Cruz Nizer ${ }^{4}$
}

Received: 30 March 2020 / Accepted: 6 May 2020 / Published online: 8 June 2020

(c) Springer-Verlag GmbH Austria, part of Springer Nature 2020

\begin{abstract}
The novel human coronavirus (SARS-CoV-2), the causative agent of COVID-19, has quickly become a threat to the public health and economy worldwide. Despite the severity of some cases, there are no current pathogen-specific antivirals available to treat the disease. Therefore, many studies have focused on the evaluation of the anti-SARS-CoV-2 activity of clinically available drugs. Here, we conducted a systematic review to describe the drug repositioning strategy against SARS-CoV-2 and to discuss the clinical impact of this approach in the current pandemic context. The systematic review was performed on March 23, 2020, using PubMed/MEDLINE, Scopus, Cochrane Library, and Biblioteca Virtual de Saúde (BVS). The data were summarized in tables and critically analyzed. After the database search, 12 relevant studies were identified as eligible for the review. Among the drugs reported in these studies, 57 showed some evidence of antiviral activity. Antivirals, especially antiretrovirals, are the main class of therapeutic agents evaluated against COVID-19. Moreover, studies have reported the antiSARS-CoV-2 activity of antitumor (16\%; 9/57), antimalarial $(7 \%, 4 / 57)$, and antibacterial $(5 \% ; 3 / 57)$ agents. Additionally, seven pharmacological agents (chloroquine, tetrandrine, umifenovir (arbidol), carrimycin, damageprevir, lopinavir/ritonavir) are in phase IV of clinical trials. Due to the evidence of the anti-SARS-CoV-2 activity of various clinically available agents, drug repositioning stands out as a promising strategy for a short-term response in the fight against the novel coronavirus.
\end{abstract}

Handling Editor: Carolina Scagnolari.

William Gustavo de Lima, Júlio César Moreira de Brito contributed equally to this article.

Electronic supplementary material The online version of this article (https://doi.org/10.1007/s00705-020-04693-5) contains supplementary material, which is available to authorized users.

William Gustavo Lima

williamgustavofarmacia@hotmail.com

Júlio César Moreira Brito

juliocmbrito@gmail.com

1 Researcher of the Group (CNPq) for Epidemiological, Economic and Pharmacological Studies of Arboviruses (EEPIFARBO), Marabá, Brazil

2 Laboratório de Radioisótopos, Departamento de Análises Clínicas e Toxicológicas, Faculdade de Farmácia, Campus Pampulha, Universidade Federal de Minas Gerais, Belo Horizonte, MG, Brazil

3 Ezequiel Dias Foundation (FUNED), Belo Horizonte, MG, Brazil

4 Carleton University, Ottawa, Ontario, Canada

\section{Introduction}

In late 2019, a cluster of pneumonia cases reported in Wuhan (China) was associated with a novel coronavirus, initially called the 2019 novel coronavirus (2019-nCov) [1]. Posteriorly, the sequence of the 2019-nCov genome revealed high similarity to SARS-CoV, the causative agent of the epidemic of severe and acute respiratory syndrome (SARS) between 2002 and 2003 in Asia. Then, the International Committee on Taxonomy of Viruses (ICTV) renamed 2019-nCov as SARS-CoV-2, and the World Health Organization (WHO) defined that this pathogen causes the coronavirus disease of 2019 (COVID-19) [2-5].

SARS-CoV-2 is responsible for a respiratory infection that can progress to severe pneumonia. COVID-19 has an estimated mortality rate of approximately $2-3.5 \%$, which increases with age and the presence of comorbidities (e.g., hypertension, cardiac insufficiency, diabetes, and asthma). By April 15, 2020, the novel coronavirus had affected 2,033,406 people and caused more than 130,000 deaths worldwide [6]. The public health calamity caused by COVID-19 has led to the exhaustion of health systems 
worldwide, forcing countries to adopt extreme measures, such as the closure of their land borders and initiating social distancing policies to slow down the spread of the disease [7].

Currently, laboratories and medical teams worldwide have focused on the repurposing of Food and Drug Administration (FDA)-approved drugs to treat the most severe cases of COVID-19, since there are no specific chemotherapeutic agents to treat this infection [1]. Indeed, drug repositioning might be a short-term alternative to fight this disease. Since the efficacy, safety, and toxicity of these drugs are already well known, the initial phases of clinical trials could be skipped, which would reduce the cost and duration of the process [8]. In general, drug repurposing is a cheaper, faster, and accessible way to make drugs available to the clinic $[9,10]$.

In this context, several clinical and preclinical studies have searched for new pharmacological alternatives against COVID-19 in clinically available drugs. However, current studies remain decentralized, and no recent review has been able to summarize the available evidence of the anti-SARSCoV-2 activity of these FDA-approved drugs. Thus, in this systematic review, we aim to describe the drug repositioning strategy against SARS-CoV-2 and its clinical impact in the current context of the COVID-19 pandemic.

\section{Methods}

We performed a systematic review according to the Cochrane Handbook [11]. The search and selection of articles, as well as extraction, analysis, and interpretation of data, were conducted according to the Preferred Reporting Items for Systematic Reviews and Meta-Analyses (PRISMA) statement [12]. PubMed/MEDLINE, Scopus, Cochrane Library, and Biblioteca Virtual de Saúde (BVS) were searched for articles investigating the antiviral activity of clinically available drugs published until March 23, 2020. We aimed to select articles describing clinical and pre-clinical tests (in vitro, in vivo, and in silico) to include the largest amount of data in this review. Additionally, we searched the Clinicatrial.gov website to identify ongoing trials with potential candidates for the drug repositioning strategy against SARS-CoV-2.

Indexed keywords from Medical Subject Headings (MeSH) were used to build search strategies. The terms "Antiviral agents" OR "Drug Repositioning" OR "Drug repurposing" were combined with the keywords "COVID19" OR "SARS-CoV-2" OR "2019-nCoV" by the use of Boolean AND between the terms, as in the example: "Drug Repositioning" AND "COVID-19". All details about the search strategies can be found in the supplementary file. To avoid losing any possible study, the reference list of all included studies and relevant reviews regarding this topic were also screened.

Two authors (W.G.L. and J.C.M.B.) independently screened the databases and extracted relevant information following the PRISMA flowchart. The degree of agreement between the evaluators was determined by the kappa coefficient (performed with a 95\% confidence interval) [13]. Discrepancies about the relevance of the sources were resolved by a third researcher (W.S.C.N.). Finally, all data of interest were summarized in tables (Tables 1,2, 3 and 4) for further critical analysis and interpretation.

\section{Results}

\section{Study selection}

As shown in Figure 1, we identified 33 articles during the initial search (30 from PubMed/MEDLINE, two from Biblioteca Virtual de Saúde, and one from Scopus). After the exclusion of repeated records and the selection of articles by the inclusion criteria (Fig. 1), 15 relevant studies were preselected. Of these, 11 were excluded following the criteria described in Figure 1, and four were selected for extraction of variables of interest [14-17]. The reference lists of included articles were analyzed, and eight new studies were identified [18-25], totaling 12 papers [14-25]. The degree of agreement between the two authors was considered substantial (kappa $=0.825)[13]$.

\section{Characteristics of included studies}

All selected studies were published in 2020 , and they describe a total of 57 drugs that showed some evidence of antiviral activity against SARS-CoV-2 (Fig. 2 and Tables 1, 2, 3 and 4) [14-25]. As shown in Figure 2A, 22 different classes of drugs showed a potential therapeutic effect against COVID-19. Antivirals, especially antiretrovirals, were the most frequently studied class of therapeutic agents $(30 \%$; $17 / 57)$. However, the activity of antitumor $(16 \%$; $9 / 57)$, antimalarial $(7 \%, 4 / 57)$, antibacterial $(5 \% ; 3 / 57)$, anticoagulant (3.5\%; 2/57), anti-inflammatory $(3.5 \% ; 2 / 57)$, phosphodiesterase (PDE)-inhibiting $(3.5 \% ; 2 / 57)$, anti-rheumatic $(3.5 \%$; $2 / 57)$, sedative-hypnotic $(3.5 \% ; 2 / 57)$, and anti-venous insufficiency $(3.5 \%$; 2/57) agents was also investigated. Other classes of drugs have also been studied against SARS-CoV-2 (i.e., anthelmintic, antiallergic, antiemetic, antiepileptic, antifungal, antihypertensive, antipsychotic, anti-hemolyticuremic syndrome, anti-angioedema, lipid-lowering, immunomodulatory, and anti-pulmonary-hypertension drugs); however, only one agent of each class was evaluated (1/57, 1.7\%) (Fig. 2A). 
Table 1 Clinical evidence of potential candidates for drug repositioning against COVID-19 (SARS-CoV-2)

\begin{tabular}{|c|c|c|c|c|}
\hline Reference & Drugs & Study design and country & No. of patients & Main outcomes \\
\hline Wang et al., 2020 [14] & $\begin{array}{l}\text { Lopinavir/ritonavir } \\
\text { Umifenovir* }\end{array}$ & $\begin{array}{l}\text { Retrospective study } \\
\text { China }\end{array}$ & 4 & $\begin{array}{l}\text { Recovery and restoration of immune function, } \\
\text { improvement of pulmonary imaging findings, } \\
\text { promotion of a negative conversion of viruses, } \\
\text { and an increase in the oxygen pressure were } \\
\text { observed after the antiviral treatment. }\end{array}$ \\
\hline Mo et al., 2020 [16] & $\begin{array}{l}\text { Lopinavir/ritonavir } \\
\text { Umifenovir** }\end{array}$ & $\begin{array}{l}\text { Retrospective study } \\
\text { China }\end{array}$ & 45 & $\begin{array}{l}\text { Only supportive care (oxygen, fluid control and } \\
\text { mechanical ventilation) was associated with } \\
\text { patient recovery. }\end{array}$ \\
\hline Shi et al., 2020 [25] & $\begin{array}{l}\text { Ganciclovir } \\
\text { Oseltamivir }\end{array}$ & $\begin{array}{l}\text { Case report } \\
\text { China }\end{array}$ & 1 & $\begin{array}{l}\text { The antiviral treatment resulted in an improve- } \\
\text { ment of pulmonary imaging findings. }\end{array}$ \\
\hline Holshue et al., 2020 [17] & Remdesivir $^{\#}$ & $\begin{array}{l}\text { Case report } \\
\text { USA }\end{array}$ & 1 & $\begin{array}{l}\text { Improvements in pulmonary imaging findings } \\
\text { and an increase in oxygen pressure were } \\
\text { observed after the treatment with remdesivir. }\end{array}$ \\
\hline Cao et al., 2020 [15] & Lopinavir/ritonavir*** & $\begin{array}{l}\text { Randomized, controlled, } \\
\text { open-label clinical trial } \\
\text { China }\end{array}$ & 199 & $\begin{array}{l}\text { Treatment with lopinavir/ritonavir did not } \\
\text { improve the clinical condition of patients } \\
\text { compared to the standard of care*** }\end{array}$ \\
\hline
\end{tabular}

*Lopinavir (400 mg) + ritonavir (100 mg), q12h, orally; associated with umifenovir (200 mg), q12h, orally. The duration of antiviral treatment was 6-15 days

**Solution containing umifenovir (20.0\%), lopinavir + ritonavir (17.4\%) and interferon (19.4\%) administered through inhalation

***In this study, 99 patients were assigned to receive lopinavir/ritonavir (400 mg and $100 \mathrm{mg}$, orally), and 100 patients were assigned to the standard of care (oxygen supplementation, noninvasive and invasive ventilation, antibiotic agents, vasopressor support, renal-replacement therapy, and extracorporeal membrane oxygenation)

\#In these studies, the therapeutic scheme used was not clearly defined

Table 2 In vitro activity of promising candidates for drug repositioning against COVID19 (SARS-CoV-2)

\begin{tabular}{llllrl}
\hline Reference & Drug & Clinical indication & \multicolumn{2}{c}{ Antiviral activity } & \multicolumn{2}{c}{\begin{tabular}{c} 
Cytotoxicity \\
\cline { 3 - 4 }
\end{tabular}} & & & $\mathrm{MOI}$ & $\mathrm{EC}_{50}(\mu \mathrm{M})$ & \\
\hline Wang et al., 2020 [18] & Remdesivir & Antiviral (Ebola) & 0.05 & 0.77 & $>100$ \\
& Ribavirin & Antiviral (hepatitis C) & 0.02 & 109.50 & $>400$ \\
& Penciclovir & Antiherpetic & 0.2 & 95.96 & $>400$ \\
& Nitazoxanide & Antiprotozoal agent & 0.8 & 2.12 & $>35.5$ \\
& Nafamostat & Anticoagulant & 0.01 & 22.50 & $>100$ \\
& Favipiravir & Antiviral (RNA virus) & 0.02 & 95.96 & $>400$ \\
& Chloroquine & Anti-malarial & 0.01 & 1.13 & $>100$ \\
Liu et al., 2020 [19] & Chloroquine & Anti-malarial & 0.01 & 2.71 & 273.20 \\
& Hydroxychloroquine & Anti-malarial & 0.01 & 4.51 & 249.50 \\
\hline
\end{tabular}

MOI, multiplicity of infection; EC50, concentration of drug required to inhibit $50 \%$ of viruses; CC50, concentration of drug required to kill $50 \%$ of mammalian cells

All studies employed Vero E6 cells
Most of the drugs with potential activity against COVID19 were identified by molecular docking $(53 \%$; 30/57) (Fig. 2B) [20-24] using the main protease (3CLpro) of SARS-CoV-2 as the molecular target (Table 3). Moreover, 39\% (22/57) (Fig. 2B) of the drugs showed an antiCOVID-19 effect in clinical trials (Table 4), and 10\% of them showed evidence of action in clinical practice $(10 \%$; 6/57) [14-17] (Table 1). Additionally, 19\% (11/57) [18, 19] (Fig. 2B) of the drugs studied showed antiviral activity in vitro. For instance, remdesivir showed the highest activity against SARS-CoV-2, inhibiting $50 \%$ of the virus at a concentration of $0.77 \mu \mathrm{M}$ [18], while ribavirin showed a less pronounced effect $(109.50 \mu \mathrm{M})$ [18] (Table 2). Therefore, the antiviral activity of only 27 compounds $(47 \% ; 27 / 57)$ has been experimentally evaluated. The remaining 30 reported drugs were identified only by theoretical methods (in sil$i c o$ ) and need proof of antiviral efficacy in further studies (Table 3).

Regarding the clinical trials of new therapeutic options against COVID-19, most drugs are in phase II $(36 \% ; 8 / 22)$ or III $(27 \% ; 6 / 22)$ (Table 4). Only seven drugs (chloroquine, tetrandrine, umifenovir (arbidol), carrimycin, 
Table 3 In silico activity of promising candidates for drug repositioning against COVID-19 (SARS-CoV-2)

\begin{tabular}{|c|c|c|c|c|}
\hline \multirow[t]{2}{*}{ Reference } & \multirow[t]{2}{*}{ Compound } & \multirow[t]{2}{*}{ Clinical indication } & \multicolumn{2}{|l|}{ In silico methods } \\
\hline & & & Molecular target & Computational method \\
\hline Chen et al., 2020 [20] & $\begin{array}{l}\text { Velpatasvir } \\
\text { Ledipasvir } \\
\text { Diosmin } \\
\text { Hesperidin } \\
\text { Teniposide } \\
\text { Etoposide } \\
\text { Venetoclax } \\
\text { Irinotecan }\end{array}$ & $\begin{array}{l}\text { Antiviral (hepatitis C) } \\
\text { Antiviral (hepatitis C) } \\
\text { Venous insufficiency } \\
\text { Venous insufficiency } \\
\text { Antitumoral } \\
\text { Antitumoral } \\
\text { Antitumoral } \\
\text { Antitumoral }\end{array}$ & SASR-CoV-2 protease (3CLpro) & Molecular docking (AutoDock Vina) \\
\hline $\mathrm{Xu}$ et al., 2020 [21] & $\begin{array}{l}\text { Nelfinavir } \\
\text { Pitavastatin } \\
\text { Perampanel } \\
\text { Praziquantel } \\
\text { Zopiclone } \\
\text { Eszopiclone }\end{array}$ & $\begin{array}{l}\text { Antiretroviral } \\
\text { Hipolipemiant } \\
\text { Antiepileptic } \\
\text { Anthelmintic } \\
\text { Sedative hypnotic } \\
\text { Sedative hypnotic }\end{array}$ & SASR-CoV-2 protease (3CLpro) & Molecular docking (AutoDock Vina) \\
\hline Liu and Wang, 2020 [23] & $\begin{array}{l}\text { Valrubicin } \\
\text { Icatibant } \\
\text { Bepotastine } \\
\text { Epirubicin } \\
\text { Epoprostenol } \\
\text { Vapreotide } \\
\text { Aprepitant } \\
\text { Caspofungin } \\
\text { Perphenazine } \\
\text { Colistin }\end{array}$ & $\begin{array}{l}\text { Antitumoral } \\
\text { Angioedema } \\
\text { Antiallergic } \\
\text { Antitumoral } \\
\text { Antiplatelet agent } \\
\text { Antitumoral } \\
\text { Antiemetic, antitumoral } \\
\text { Antifungal } \\
\text { Antipsychotic } \\
\text { Antibiotic }\end{array}$ & SASR-CoV-2 protease (3CLpro) & Molecular docking (AutoDock Vina) \\
\hline Li et al., 2020 [22] & $\begin{array}{l}\text { Nelfinavir } \\
\text { Prulifloxacin } \\
\text { Bictegravir } \\
\text { Tegobuvir }\end{array}$ & $\begin{array}{l}\text { Antiretroviral } \\
\text { Antibiotic } \\
\text { Antiretroviral } \\
\text { Antiviral (hepatitis C) }\end{array}$ & SASR-CoV-2 protease (3CLpro) & Molecular docking (AutoDock Vina) \\
\hline Beck et al., 2020 [24] & $\begin{array}{l}\text { Atazanavir } \\
\text { Ganciclovir } \\
\text { Darunavir }\end{array}$ & $\begin{array}{l}\text { Antiretroviral } \\
\text { Antiretroviral } \\
\text { Antiretroviral }\end{array}$ & RdRp, helicase & MT-DTI model \\
\hline
\end{tabular}

3CLpro, 3-chymotrypsin-like protease; RdRp, RNA-dependent RNA polymerase; MT-DTI, Molecule Transformer-Drug Target Interaction

damageprevir, lopinavir/ritonavir) are in phase IV of clinical trials (Table 4). Interestingly, two of these agents in advanced clinical studies, umifenovir (Arbidol) and the association lopinavir/ritonavir, have demonstrated previous evidence of action. Wang et al. [14] reported that the use of arbidol in combination with lopinavir/ritonavir inhibits the aggravation of pneumonia caused by SARS-CoV-2 and promotes a virus-negative conversion in patients from China. Arbidol has also shown a potent in vitro effect against SARS-CoV-2, inhibiting the virus up to 60 times compared to the untreated control at concentrations ranging from 10 to $30 \mu \mathrm{M}$ [26].

\section{Discussion}

The novel coronavirus (SARS-CoV-2), the causative agent of COVID-19, has quickly become a threat to the public health and economy worldwide [7, 27]. Recent clinical reports have shown that SARS-CoV-2 causes mild, selflimiting respiratory tract illness as well as severe progressive pneumonia, which can progress to multiorgan failure and death [1]. Despite the severity of some cases, there are no current pathogen-specific antivirals available to treat this disease [1]. Therefore, many studies have focused on 
Table 4 Clinical trials of promising candidates for drug repositioning against COVID-19 (SARS-CoV-2)

\begin{tabular}{|c|c|c|c|c|}
\hline ID & Population & Drug & Indication & Phase \\
\hline NCT04292899 & 400 & Remdesivir & Antiviral (Ebola and Marburg) & III \\
\hline NCT04273529 & 100 & Thalidomide & Immunomodulatory agent, antiangiogenic, TNF blocking agent. & II \\
\hline NCT04308317 & 60 & Tetrandrine & Anti-inflammatory, immunologic and antiallergenic & IV \\
\hline NCT04318015 & 400 & Hydroxychloroquine & Antimalarial and anti-inflammatory (Rheumatoid arthritis and lupus) & III \\
\hline NCT04316377 & 202 & Chloroquine & Antimalarial and anti-inflammatory (Rheumatoid arthritis and lupus) & IV \\
\hline NCT04260594 & 380 & Umifenovir (Arbidol) & Antiviral (influenza) & IV \\
\hline NCT04286503 & 520 & Carrimycin & Antibiotic (macrolide) & IV \\
\hline NCT04303299 & 80 & Oseltamivir & Antiviral (influenza) & III \\
\hline NCT04303299 & 80 & Favipiravir & Antiviral (influenza) & III \\
\hline NCT04311177 & 516 & Losartan & Antihypertensive & II \\
\hline NCT04275414 & 20 & Bevacizumab & Antitumoral (anti-VEGF) & II \\
\hline NCT04311697 & 20 & Aviptadil & Erectile dysfunction treatment & II \\
\hline NCT04305457 & 240 & Nitric oxide Gas & Pulmonary hypertension treatment & II \\
\hline NCT04320277 & 60 & Baricitinib & Anti-inflammatory (rheumatoid arthritis) & III \\
\hline NCT04291729 & 11 & Danoprevir & Antiviral (hepatitis C) & IV \\
\hline NCT04286503 & 520 & Ritonavir & Antiretroviral & IV \\
\hline NCT04288713 & - & Eculizumab & $\begin{array}{l}\text { Hemolytic-uremic syndrome and paroxysmal nocturnal hemoglobinuria } \\
\text { treatment }\end{array}$ & - \\
\hline NCT04317092 & 330 & Tocilizumab & Rheumatoid arthritis treatment & II \\
\hline NCT04286503 & 520 & Lopinavir & Antiretroviral & IV \\
\hline NCT04276688 & 70 & Ribavirin & Antiviral (hepatitis C) & II \\
\hline NCT04315298 & 400 & Sarilumab & Rheumatoid arthritis treatment & II \\
\hline
\end{tabular}

All data were obtained from a manual search in clinicaltrial.gov

the evaluation of the anti-SARS-CoV-2 activity of clinically available drugs [1].

After the analysis of the selected studies, we identified 57 molecules with potential antiviral activity against SARS-CoV-2. Of these, only six drugs (lopinavir/ritonavir, umifenovir (arbidol), remdesivir, chloroquine, and hydroxychloroquine) have shown promising results in preclinical trials and have clinically lessened the symptoms of COVID- 19. Since the other FDA-approved drugs reported in this review showed weak activity against COVID-19, we have chosen to discuss only the most promising molecules.

Lopinavir and ritonavir are antiretrovirals widely used as a combination drug to treat human immunodeficiency virus (HIV) infections. Lopinavir is an HIV type 1 aspartate protease inhibitor, and ritonavir increases its plasma half-life through the inhibition of cytochrome P450 [28]. Previous studies showed that lopinavir inhibits the 3-chymotrypsinlike protease, which is involved in viral replication and is highly conserved among members of different viral species [29]. Lopinavir inhibited the replication of MERS-CoV and SARS-CoV in Huh7 cells (human liver strain) in a dosedependent manner, with an $\mathrm{EC}_{50}$ of $8.0 \mu \mathrm{M}$ for both viruses [29]. Moreover, lopinavir/ritonavir significantly reduced the mortality rate of mice infected with MERS-CoV, suggesting a strong in vivo antiviral effect [30].
Little is known about the activity of lopinavir/ritonavir against SARS-CoV-2 and its effectiveness (Table 1). For instance, Wang et al. [14] showed that the use of lopinavir/ ritonavir considerably improved the clinical condition of patients with COVID-19. However, arbidol, a broad-spectrum antiviral with activity against several enveloped and non-enveloped viruses (e.g., influenza virus, adenovirus, avian coronavirus, and hepatitis $B$ and $C$ viruses) [31], was also administered to the patients $(n=4)$. The combination of lopinavir/ritonavir with arbidol makes it difficult to associate the observed antiviral effect to lopinavir/ritonavir or to its synergistic effect with arbidol. In contrast, Mo et al. [16] showed that the clinical improvement of patients with COVID-19 was more associated with supportive measures, such as mechanical ventilation and oxygen supplementation, than with the use of lopinavir/ritonavir. Likewise, a study of 199 hospitalized adult patients with confirmed SARS-CoV-2 infection showed that the use of lopinavir/ritonavir does not increase the effectiveness of the standard treatment [15]. These findings confirm that lopinavir/ritonavir has low clinical efficacy and is not a therapeutic option to treat COVID-19. However, the efficacy related to the use of these antiretrovirals as a combination therapy with other drugs should be elucidated in future studies. 


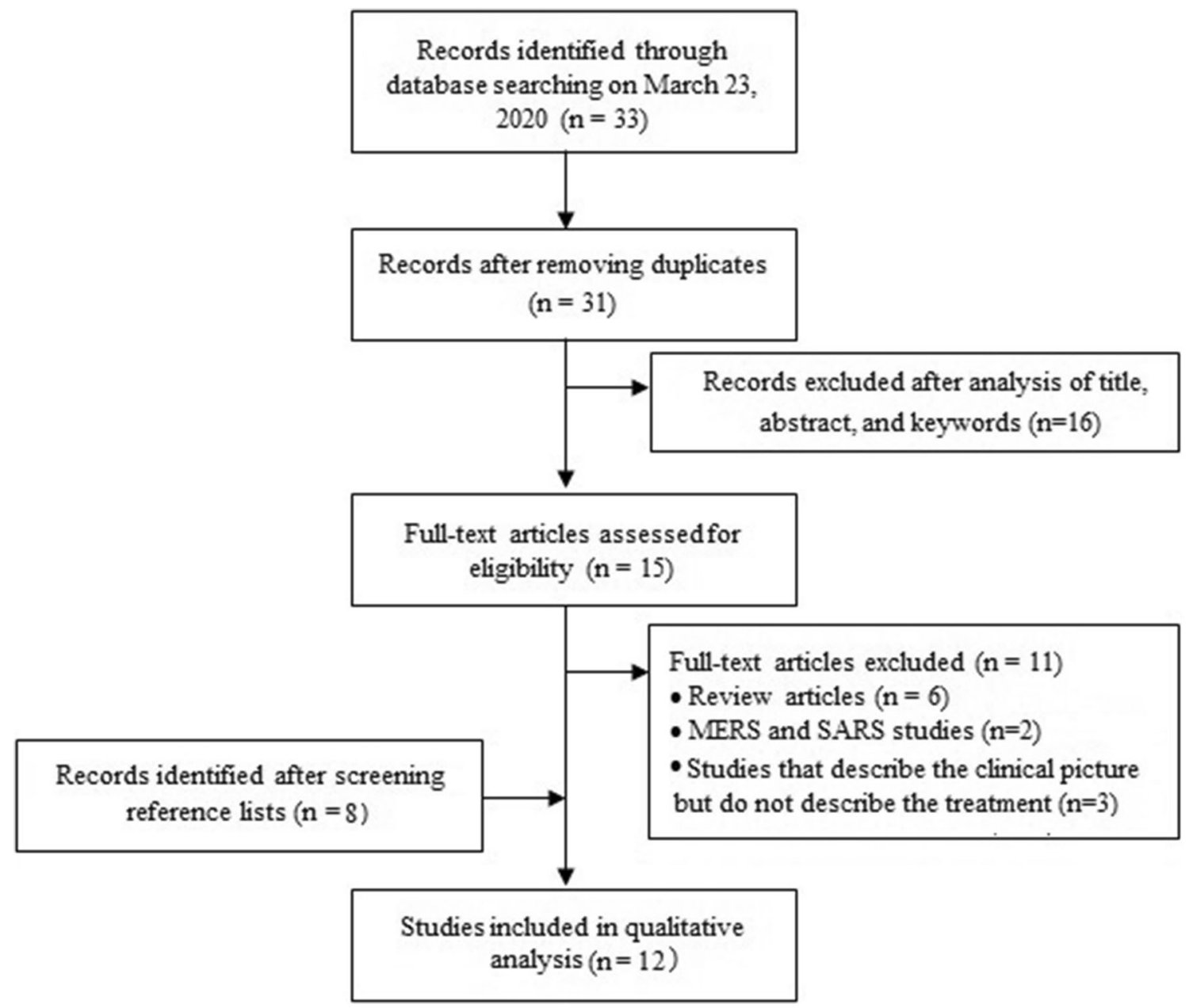

Fig. 1 Flowchart of the selection of articles for the systematic review following the PRISMA criteria [12]
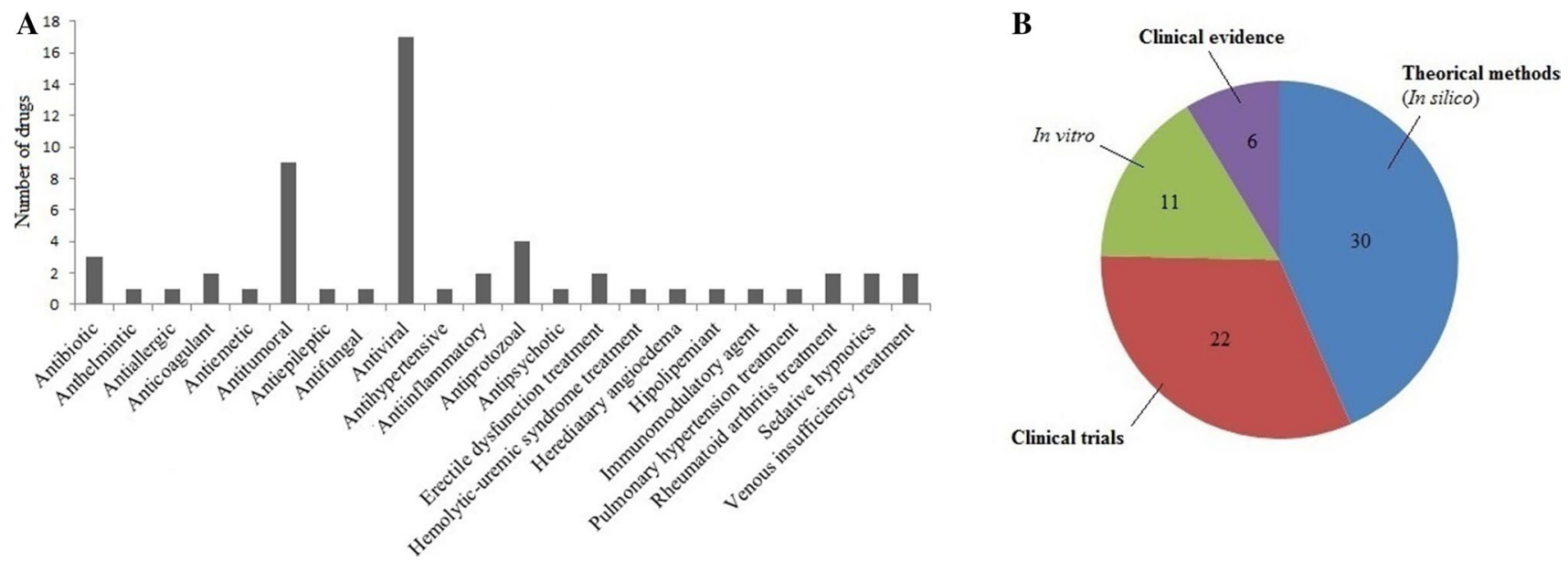

Fig. 2 (A) Number of drugs in each therapeutic class with clinical or preclinical evidence of activity against SARS-CoV-2. (B) Distribution of drugs currently studied against COVID-19 according to the type of study 
Arbidol (umifenovir) is an anti-influenza agent that has been used in China and Russia for many years. It interacts with the viral hemagglutinin (HA) and inhibits the fusion of the viral particle with the plasma membrane [32]. This drug inhibited crucial stages of the SARS-CoV-2 replication cycle in vitro in a concentration ranging from 10 to $30 \mu \mathrm{M}$ [26]. Also, a study has indicated that arbidol significantly lessened pneumonia associated with COVID-19 [14]. These results have stimulated the initiation of clinical trials with this medicine (Table 4). For instance, a Chinese group of the Ruijin Hospital is currently conducting a phase IV study to evaluate the efficacy and safety of arbidol hydrochloride tablets in treating pneumonia in 380 patients with COVID19 (Clinicaltrial.gov, NCT04260594).

Previous in vitro studies have indicated that arbidol shows significant activity against other coronaviruses. Herein, a research group showed that this compound negatively affects the early stages of viral replication of SARS-CoV at a concentration of $50 \mu \mathrm{g} / \mathrm{ml}$. This study also highlighted the stronger antiviral activity of arbidol mesylate compared to arbidol as an alkaline preparation [33]. These preliminary results indicate that arbidol is a promising candidate for drug repositioning against SARS-CoV-2. However, further studies are required to assess the difference in the effectiveness of arbidol and arbidol mesylate in patients with COVID-19.

Remdesivir is a broad-spectrum prodrug developed to treat infections caused by Ebola virus and Marburg virus. Its active ingredient (GS-441524) decreases the production of RNA by interfering with viral RNA polymerase and evading proofreading by viral exonuclease [34]. Recent studies have shown that remdesivir inhibits the replication of SARS-CoV and MERS-CoV in human lung cells [35]. Wang et al. [18] showed that remdesivir has potent activity against SARS-CoV-2 in kidney cells, with an $\mathrm{EC}_{50}$ of $0.77 \mu \mathrm{M}$. Additionally, this drug induced the clinical remission of the symptoms of COVID-19 in the first reported case in the USA (Table 1) [17]. Due to these promising results, a phase III clinical trial has evaluated the antiviral activity of remdesivir and its safety in patients with severe COVID-19. This study is assessing the ability of remdesivir to normalize body temperature and oxygen saturation in 400 hospitalized adult patients (Clinicaltrial.gov, NCT04292899). Therefore, the results of this clinical trial can guide the prescription of remdesivir as an anti-SARS-CoV-2 agent in the future.

Chloroquine and hydroxychloroquine are antimalarial agents widely used to treat rheumatic diseases and have also shown promising activity against COVID-19 [36]. The first evidence of their antiviral effect against coronavirus was reported in 2004 when Keyaerts and collaborators showed that chloroquine inhibited the in vitro replication of SARS$\mathrm{CoV}$ on Vero cells E6. In this study, chloroquine negatively affected SARS-CoV-2 at a concentration of $8 \mu \mathrm{M}$ [37]. Interestingly, chloroquine inhibited the virus when the cells were treated with the drug before or after exposure to SARS-CoV, suggesting prophylactic and therapeutic effects [38]. This drug also affects the entry and replication of SARS-CoV-2, with an $\mathrm{EC}_{50}$ of $1.13 \mu \mathrm{M}$ [18]. Moreover, hydroxychloroquine, a less toxic derivative of chloroquine, is also able to inhibit the entry and replication of SARS-CoV-2 with an $\mathrm{EC}_{50}$ of $4.51 \mu \mathrm{M}$ (Table 2) [19]. Additionally, the preclinical results have suggested that this antimalarial blocks the transport of SARS-CoV-2 from endosomes to endolysosomes, which is a process required to release the viral genome [18, 19].

The promising in vitro results of chloroquine and hydroxychloroquine have motivated the initiation of clinical studies of these substances (Table 4). One of these studies evaluates the prophylactic effect of the oral use of chloroquine in 10,000 patients against SARS-CoV-2 (Clinicaltrial. gov, NCT04303507). Additionally, several clinical trials have evaluated the prophylactic use of hydroxychloroquine (Clinicaltrial.gov, NCT04318015, and NCT04318444), its therapeutic use in monotherapy (Clinicaltrial.gov, NCT04315896), or the effect of its combination with other antivirals (Clinicaltrial.gov, NCT04303299, NCT04321278 and NCT0430127, and NCT0430127 and NCT0430127) against COVID-19.

The rapid popularization of these preliminary results has led to a massive and irrational demand for chloroquine and hydroxychloroquine. In Brazil, for example, after the first reports of the clinical effectiveness of hydroxychloroquine against COVID-19, this drug quickly sold out in pharmacies, which has compromised patients who use this drug continually to treat autoimmune diseases. This irrational demand caused the Agência Nacional de Vigilância Sanitária (ANVISA) to include these two drugs in the list of controlled substances to prevent their use to treat COVID-19 without prescription or proof of effectiveness. This situation highlights the importance of controlling the release of preliminary results, especially in the panic scenario created by the pandemic.

Although several studies have identified clinically available agents that are active against SARS-CoV-2 infections, supportive therapy remains essential. For instance, mechanical ventilation and oxygen supplementation have been critical to the survival of patients with severe COVID-19. Mo et al. [16] showed that that oxygen supplementation and noninvasive or invasive ventilation have generated similar results to the use of an antiretroviral with known in vitro activity against SARS-CoV-2. Additionally, Wang et al. [14] showed that the clinical recovery of patients with COVID19 is more associated with supportive therapies than with the use of antiviral agents. However, the identification of available drugs with anti-SARS-CoV-2 activity and their use in association with supportive therapies should be considered. Also, the development of faster diagnostic tools to test 
for COVID-19 might be crucial, since some of the candidates for drug repositioning must be administered early in the course of infection. Thus, better testing methodologies could lead to the early administration of drugs and improve the treatment of COVID-19.

\section{Conclusion}

The rapid spread of SARS-CoV-2 worldwide has put pressure on research centers to develop effective therapies and vaccines for the treatment of SARS-CoV-2. Drug repositioning is a promising short-term strategy in the fight against the novel coronavirus. However, supportive measures are essential mainly for severe COVID-19 patients, and the implementation of drug repositioning should be done only if the efficacy of the drugs have been proven. Although lopinavir/ ritonavir had low anti-SARS-CoV-2 activity, arbidol, remdesivir, and chloroquine/hydroxychloroquine showed promising effects against this coronavirus. Therefore, the outcomes of the ongoing clinical trials are urgently needed to evaluate the best treatment options for COVID-19. Furthermore, additional studies of the antiviral activity of molecules that have shown a promising in silico effect may increase the therapeutic arsenal against the novel coronavirus.

Acknowledgments We thank UFMG/Pharmacy school-PPGCF for the availability of bibliographic support. W.G.L. is grateful to Coordenação de Aperfeiçoamento de Pessoal do Nível Superior (CAPES) for a Ph.D. fellowship.

Author contributions All authors contributed to the development, analysis, and drafting of this article.

Funding None.

\section{Compliance with ethical standards}

Conflict of interest All authors report that they do not have any conflicts of interest.

Ethical approval This article does not contain any studies with human participants or animals performed by any of the authors.

\section{References}

1. Zhu N, Zhang D, Wang W et al (2020) A novel coronavirus from patients with pneumonia in China, 2019. N Engl J Med 382:727733. https://doi.org/10.1056/NEJMoa2001017

2. De Wit E, Van Doremalen N, Falzarano D, Munster VJ (2016) SARS and MERS: recent insights into emerging coronaviruses. Nat Rev Microbiol 14:523-534. https://doi.org/10.1038/nrmic ro.2016.81

3. de Wilde AH, Snijder EJ, Kikkert M, van Hemert MJ (2018) Host factors in coronavirus replication. In: Ahmed R, Akira S, Aktories K, Casadevall A, Compans RW, Galan JE,
Garcia-Sastre A, Malissen B, Rappuoli R (eds) Current topics in microbiology and immunology, 3rd edn. Springer Verlag, Switzerland, pp 1-42

4. Chen N, Zhou M, Dong X et al (2020) Epidemiological and clinical characteristics of 99 cases of 2019 novel coronavirus pneumonia in Wuhan, China: a descriptive study. Lancet 395:507-513. https://doi.org/10.1016/S0140-6736(20)30211-7

5. Paules CI, Marston HD, Fauci AS (2020) Coronavirus InfectionsMore Than Just the Common Cold. JAMA - J Am Med Assoc 323:707-708. https://doi.org/10.1001/jama.2020.0757

6. Worldometer (2020) Coronavirus Cases. Worldometer. https:// www.worldometers.info/coronavirus/. Accessed 15Apr 2020

7. Meraw S (2020) The global macroeconomic impacts of COVID19: Seven scenarios. Brookings. https://www.brookings.edu/resea $\mathrm{rch} /$ the-global-macroeconomic-impacts-of-covid-19-seven-scena rios/. Accessed 26 Mar 2020

8. Chong CR, Sullivan DJ (2007) New uses for old drugs. Nature 448:645-646. https://doi.org/10.1038/448645a

9. Padhy BM, Gupta YK (2011) Drug repositioning: Re-investigating existing drugs for new therapeutic indications. J Postgrad Med 57:153-160. https://doi.org/10.4103/0022-3859.81870

10. Lima WG, Alves-Nascimento LA, Andrade JT et al (2019) Are the Statins promising antifungal agents against invasive candidiasis? Biomed Pharmacother 111:270-281. https://doi.org/10.1016/j. biopha.2018.12.076

11. Higgins JPT, Green S (editors) (2011) Cochrane handbook for systematic reviews of interventions Version 5.1.0 [updated March 2011]. The Cochrane Collaboration, 2011. https://training.cochr ane.org/handbook. Accessed 15 Apr 2020

12. Liberati A, Altman DG, Tetzlaff J et al (2009) The PRISMA statement for reporting systematic reviews and meta-analyses of studies that evaluate health care interventions: explanation and elaboration. PLoS Med 6:e1000100. https://doi.org/10.1371/journ al.pmed. 1000100

13. Landis Richard, Koch GG (1977) The measurement of observer agreement for categorical data. Biometrics 33:159-174. https:// doi.org/10.2307/2529310

14. Wang Z, Chen X, Lu Y et al (2020) Clinical characteristics and therapeutic procedure for four cases with 2019 novel coronavirus pneumonia receiving combined Chinese and Western medicine treatment. Biosci Trends 14:64-68. https://doi.org/10.5582/ bst.2020.01030

15. Cao B, Wang Y, Wen D et al (2020) A trial of lopinavir-ritonavir in adults hospitalized with severe covid-19. N Engl J Med. https ://doi.org/10.1056/NEJMoa2001282

16. Mo P, Xing Y, Xiao Y et al (2020) Clinical characteristics of refractory COVID-19 pneumonia in Wuhan, China. Clin Infect Dis 5:4. https://doi.org/10.1093/cid/ciaa270

17. Holshue ML, DeBolt C, Lindquist S et al (2020) First case of 2019 novel coronavirus in the United States. N Engl J Med 382:929 936. https://doi.org/10.1056/NEJMoa2001191

18. Wang M, Cao R, Zhang $L$ et al (2020) Remdesivir and chloroquine effectively inhibit the recently emerged novel coronavirus (2019nCoV) in vitro. Cell Res. 30:269-271

19. Liu J, Cao R, Xu M et al (2020) Hydroxychloroquine, a less toxic derivative of chloroquine, is effective in inhibiting SARS-CoV-2 infection in vitro. Cell Discov 6:16. https://doi.org/10.1038/s4142 1-020-0156-0

20. Chen YW, Yiu C-PB, Wong K-Y (2020) Prediction of the SARSCoV-2 (2019-nCoV) 3C-like protease (3CLpro) structure: virtual screening reveals velpatasvir, ledipasvir, and other drug repurposing candidates. F1000Research 9:129. https://doi.org/10.12688/ f1000research.22457.1

21. Xu Z, Peng C, Shi Y, et al (2020) Nelfinavir was predicted to be a potential inhibitor of 2019-nCov main protease by an integrative approach combining homology modelling, molecular 
docking and binding free energy calculation. bioRxiv. https://doi. org/10.1101/2020.01.27.921627

22. Li Y, Zhang J, Wang $\mathrm{N}$ et al (2020) Therapeutic drugs targeting 2019-ncov main protease by high-throughput screening. bioRxiv. https://doi.org/10.1101/2020.01.28.922922

23. Liu X, Wang X-J (2020) Potential inhibitors for 2019-nCoV coronavirus $\mathrm{M}$ protease from clinically approved medicines. bioRxiv 5:12. https://doi.org/10.1101/2020.01.29.924100

24. Beck BR, Shin B, Choi Y et al (2020) Predicting commercially available antiviral drugs that may act on the novel coronavirus (2019-nCoV), Wuhan, China through a drugtarget interaction deep learning model. bioRxiv. https://doi. org/10.1101/2020.01.31.929547

25. Shi H, Han X, Zheng C (2020) Evolution of CT manifestations in a patient eecovered from 2019 novel coronavirus (2019-nCoV) pneumonia in Wuhan, Chinaa. Radiology 295:20. https://doi. org/10.1148/radiol.2020200269

26. Tingting S (2020) Li Lanjuan's team: Abidol and darunavir can effectively inhibit coronavirus. China News Network. http://www. sd.chinanews.com/2/2020/0205/70145.html. Accessed 26 Mar 2020 (in Chinese)

27. Rodríguez-Morales AJ, MacGregor K, Kanagarajah S et al (2020) Going global-Travel and the 2019 novel coronavirus. Travel Med Infect Dis. 33:101578. https://doi.org/10.1016/j.tmaid.2020.10157 8

28. Cvetkovic RS, Goa KL (2003) Lopinavir/ritonavir: a review of its use in the management of HIV infection. Drugs 63:769-802. https ://doi.org/10.2165/00003495-200363080-00004

29. De Wilde AH, Jochmans D, Posthuma CC et al (2014) Screening of an FDA-approved compound library identifies four smallmolecule inhibitors of Middle East respiratory syndrome coronavirus replication in cell culture. Antimicrob Agents Chemother 58:4875-4884. https://doi.org/10.1128/AAC.03011-14

30. Chan JF-W, Yao Y, Yeung M-L et al (2015) Treatment With Lopinavir/Ritonavir or Interferon- $\beta 1 \mathrm{~b}$ improves outcome of MERS$\mathrm{CoV}$ infection in a nonhuman primate model of common marmoset. J Infect Dis 212:1904-1913. https://doi.org/10.1093/infdi s/jiv392
31. Boriskin Y, Leneva I, Pecheur E-I, Polyak S (2008) Arbidol: a broad-spectrum antiviral compound that blocks viral fusion. Curr Med Chem 15:997-1005. https://doi.org/10.2174/0929867087 84049658

32. Blaising J, Polyak SJ, Pécheur EI (2014) Arbidol as a broadspectrum antiviral: An update. Antivir Res. 107:84-94. https:// doi.org/10.1016/j.antiviral.2014.04.006

33. Khamitov RA, Loginova SI, Shchukina VN et al (2008) Antiviral activity of arbidol and its derivatives against the pathogen of severe acute respiratory syndrome in the cell cultures. Vopr Virusol 53:9-13 (Article in Russian)

34. Hoenen T, Groseth A, Feldmann H (2019) Therapeutic strategies to target the Ebola virus life cycle. Nat Rev Microbiol 17:593606. https://doi.org/10.1038/s41579-019-0233-2

35. Agostini ML, Andres EL, Sims AC et al (2018) Coronavirus susceptibility to the antiviral remdesivir (GS-5734) is mediated by the viral polymerase and the proofreading exoribonuclease. MBio 9:e00221-18. https://doi.org/10.1128/mBio.00221-18

36. Schrezenmeier E, Dörner T (2020) Mechanisms of action of hydroxychloroquine and chloroquine: implications for rheumatology. Nat Rev Rheumatol 16:155-166. https://doi.org/10.1038/ s41584-020-0372-x

37. Keyaerts E, Vijgen L, Maes P et al (2004) In vitro inhibition of severe acute respiratory syndrome coronavirus by chloroquine. Biochem Biophys Res Commun 323:264-268. https://doi. org/10.1016/j.bbrc.2004.08.085

38. Vincent MJ, Bergeron E, Benjannet S et al (2005) Chloroquine is a potent inhibitor of SARS coronavirus infection and spread. Virol J 2:69. https://doi.org/10.1186/1743-422X-2-69

Publisher's Note Springer Nature remains neutral with regard to jurisdictional claims in published maps and institutional affiliations. 